\title{
Capacity building on the field of Life Sciences - fields to articulate project ideas for CARPE partners
}

\author{
János Felföldi ${ }^{1}$ \\ 1 Institute of Applied Informatics and Logistics, Faculty of Economics and Business, \\ University of Debrecen, Hungary
}

\begin{abstract}
Within the Faculty of Economics and Business of the Univesity of Debrecen (UD) our research group focuses on Lifestyle and Health Sciences. We define health as a complex psycho-bio and social phenomenon and the overall goal is to promote, assist and implement Sustainable Lifestyle. However Sustainable Lifestyle has many corresponding scientific sub-categories, beyond our activities we concentrate on

(1) the present trends and future potential of sustainable food consumption, covering special consumer demands on functional food, organic, ethical , fairly traded, LOHAS-LOVOS and local products, plant-based diet and cultured (lab-grown) meat, sustainable european traditional pig (Fatty Pig) etc.,

(2) short food supply chain,

(3) renewable energy, and

(4) the economic, social, health preserving effects of physical activity.

Our aim is to run professional lifestyle studies focusing on actual research issues of Health Industry. Within the scope of Sustainable Lifestyle we wish to contribute to general awareness-raising about Health Economy with a special attention on social health-consciousness. Our proposal initiate seeks future collaborations with CARPE members in the form of
\end{abstract}

1. Organisation of joint educational (bachelor, master and PhD) events;

2. Exchange of students;

3. Exchange of teaching and research staff;

5. Exchange of articles, publications and other scientific information;

6. Organisation of common scientific conferences.

Keywords: Sustainability, Short Food Supply Chain, Consumer Behaviour. 


\section{Introduction}

The University of Debrecen is recognising the mutual benefits to be gained through strengthening the collaboration between higher education institutions, companies or other research institutes. Therefore our current project proposal focuses on establishing and deepening partnership and cooperation with the aim of stimulating $\mathrm{R}+\mathrm{D}$ activities and enhancing innovation..

The Faculty of Economics and Business is the youngest faculty of the Debrecen University and the largest one regarding the number of its students (cc. 4000 students). The Faculty was created by the integration of the Faculty of Applied Economics and Rural Development, with the Faculty of Economics and Business Administration as of 1 August, 2014. As a result, the academic experience and scientific research of these two legal predecessors made up a pool of joint resources that provides a wide spectrum of educational and research services for both students and stakeholders. The educational fields of the Department encompass agriculture, economic, sports sciences, and humanities. The fame and popularity of the Faculty are also in evidence by the multiple academic fields on offer as well as the fact that the majority of our students continue their studies at the Faculty.

Our research community is exploring the academic field of Lifestyle and Health Sciences. Within this wide concept our team concentrates on the topic of Helath defined as a complex psycho-bio and social phenomenon offering a tool to promote, assist and implement Sustainable Lifestyle. However Sustainable Lifestyle has many other corresponding scientific sub-categories the current proposal has chosen certain topics of Sustainablity as potential future research activities together with CARPE members.

\subsection{Sustainable food consumption}

We are interested in the present trends and future potential of sustainable food consumption, covering special consumer demands on functional food, organic, ethical and/or fairly traded products, in the size of LOHAS-LOVOS community in the partner country and in the structure and movement of local products. We would like to explore the potential and present populatrity of plant-based diet and cultured (lab-grown) meat. We could introduce the success of sustainable european traditional pig (Fatty Pig) as a (Hungarian) best practice.

\subsection{Short food supply chain}

With the help of analyzing the demand for sustainable food categories (see above) we could explore the insitutional system (members and stakeholders) and infrastures of locally growned/produced articles with a territorial focus of in CARPE countries. As short food supply chains get more attention these days it would be important to see good examples in 
partner countries and set a stragety in order to further assist the expansion of short supply chains in the agrifood sector.

\section{3. Renewable energy}

As set in the EU2020 srtategy of the Europen Union renewable energy sector should be strengthend all over Europe. However Hungary is keen on to meet the target goals it still has space to deveope the usage of renewable erergy sources within the country. We would like to meet smart examples of the partnership that could be adoptable in Hungary, too.

\subsection{Physical activity}

Similar to the renewable energy sector in case of physical activity Hungary has bad scores comparing to other EU member countries. It is commonly known that physical activity has got a relevant effects on the economy. Therefore social and health preserving outcomes of more or less physical activity should be analysed among CARPE members.

\section{Potential means and areas of cooperation}

During a future project university students of various levels (bachelor, master, $\mathrm{PhD}$ ) and research fellows could be involved in explorative activities (case studies, market research, collecting best practices, focus groups, etc.). Our aim is to run professional lifestyle studies focusing on actual research issues of the above mentioned topics. Our intention is that the results and findings of these studies will contribute to the development of the Sustainable Lifestyle.

We recommend the following potential means and areas of cooperation for the CAPR conference:

\subsection{Organisation of joint educational (bachelor, master and PhD) events}

2.1.1. Organisation of workshops and meetings for students and research fellows of the partner Univerities in order to support their research activities and broaden their overview upon a certain topic. These events could support the networking activities of students and professionals of the Faculties, and give opportunity to share information and research results with each other and to come up with new ideas regarding future activities.

2.1.2. Defining common research/thesis/dissertation topics for the students of the two Faculties.

2.1.3. Providing supervisory activities for the students of the Partner institution: linking students and research fellows and researchers and research fellows with the 
relevant knowledge of the Partner institution in order to promote international aspect of the research and exchanging views on various issues.

\subsection{Exchange of students}

Student mobility and internship opportunity for students at the Partner Universities and companies of the certain country.

\subsection{Exchange of teaching and research staff}

Short-term mobility of teaching and research staff from/to the Partner University at the above-mentioned topics.

\subsection{Exchange of publications and other scientific information}

Common publications at the above-mentioned research topics, such as Sustainability, Sustainable Lifestyle, Sustainable Food Consumption, Effects of Physical activity, Health Industry, Health Economy, etc.

2.5. Organisation of common scientific conferences such as Annual conference of Nutrition Marketing - Debrecen, Hungary.

\section{Expected results}

As an outcome of a future cooperation the Faculty of Economics and Business would like to further deepen CARPE membership and benefit from the knowledge and experience of the network of universities. Due to a strengthend cooperation between the partners the number of internation publications and cross-national projects will rise effecting an increased reputation of the CARPE platform, too. 